\title{
Heterosexual sexual behaviour in a sample of homosexually active men
}

\author{
RAY FITZPATRICK,${ }^{*} \dagger$ GRAHAM HART, $\ddagger$ MARY BOULTON, $\S$ JOHN MCLEAN, $\S$ \\ JILL DAWSON* \\ From the Department of Community Medicine and General Practice, Radcliffe Infirmary, University of \\ Oxford,* Nuffield College, $\dagger$ Oxford, Academic Department of Genito-Urinary Medicine, University College and \\ Middlesex School of Medicine, $\ddagger$ London, and the Academic Department of Community Medicine, St Mary's \\ Hospital, $\$$ London, UK
}

SUMMARY Three hundred and fifty six homosexually active men were recruited in 1988 for a study by interview of sexual behaviour. Thirty two per cent had homosexual passive anal sex in the previous month and $60 \%$ in the year before interview. Anal sex and unprotected anal sex were more common with regular than non-regular partners. Heterosexual sex was reported by $4 \%$ of men in the last month and $10 \%$ for the last year. Sixteen per cent of heterosexually active men reported anal sex with a female partner. Fewer men described themselves as bisexual than would be expected from the sample's recent sexual histories. More attention is needed to the definition and measurement of "bisexuality" to understand its role in HIV transmission.

In England homosexual men constituted the first and, to date, the largest risk group for AIDS. Studies have focused on the role of homosexual anal intercourse as by far the most important mode of transmission within this group. ${ }^{1}$ Intravenous drug use has been seen as a more important route for heterosexual spread of HIV than heterosexual sex amongst homosexual men. ${ }^{2}$ However, in view of the evidence in the United States that heterosexual cases are increasing at a faster rate than other risk groups, ${ }^{3}$ bisexual sexual behaviour needs investigation. Partly on the basis of lower rates of HIV infection found amongst bisexual compared with homosexual men, it has been suggested that "two distinct populations exist". ${ }^{4}$ However, few studies are clear about their criteria for these two groups and they are often merged in analyses of behaviour. This may be because bisexuality is a particularly problematic sexual identity. ${ }^{5}$ This paper reports the extent and nature of heterosexual sex in a sample of homosexually active men.

\section{Methods and sample}

The criterion ror inclusion in this study was any man who has had sex of any kind with another man in the

Address for reprints: Dr R Fitzpatrick, Nuffield College, Oxford OX1 INF, UK.

Accepted for publication 30 June 1989 previous five years. The sample reported here comprises 356 men recruited from a diverse range of sources. One hundred and ninety eight men $(56 \%)$ volunteered from gay pubs, clubs and gay organisations; 82 men $(23 \%)$ were recruited from genitourinary clinics and $76(21 \%)$ were referrals from those already interviewed ("snowball sampling"). Four main towns and cities were used to recruit the sample: London $(52 \%)$, Manchester (21\%), Oxford (13\%) and Northampton (5\%). Nine per cent were recruited from areas around these four centres. Interviews were conducted in 1988.

Interviews focused upon sexual behaviour in the previous month and in the previous year. Information was gathered by means of a check list of sexual behaviours and respondents were asked, in relation to the last month, to describe in detail their sexual behaviour with each of their partners in turn. Men were first of all asked about regular partners with whom they were currently in a relationship. They were then asked about other partners.

The mean age of the sample was 32.9 years (SD 10.7) with a range from 16 to 67 . The sample was predominantly middle class with $87 \%$ of men in Social Class I, II, IIINM, according to the Registrar General's Classification of Occupations. When asked how they preferred to describe their sexual orientation from a standardised check list, $276(78 \%)$ chose gay, $37(10 \%)$ chose homosexual and $31(9 \%)$ bisexual. A further 12 (3\%) preferred no designation or unique terms not 
included in the check list such as "transexual'. Men were asked to rate themselves on the Kinsey scale. Two hundred and ninety nine (84\%) described themselves as exclusively homosexual in terms of sexual activities, and $227(64 \%)$ as exclusively homosexual in terms of fantasies and attractions. The rest of the men described themselves in terms of varying degrees of both homosexual and heterosexual activity and feelings. Thirty five men (10\%) were currently married, separated or divorced.

\section{Results}

\section{Homosexual sex}

One hundred and fifteen men (32\%) had passive anal sex in the month before interview. Ninety four $(26 \%)$ had passive anal sex with a regular partner and 33 $(9 \%)$ with a non-regular partner. Seventy four $(21 \%)$ had passive anal sex without a condom. Unprotected passive anal sex much more commonly occurred with regular partners ( $59 \mathrm{men}, 17 \%)$ than with non-regular partners (18 men, $5 \%)$.

A similar pattern was described by men with regard to active anal sex. One hundred and thirteen men $(32 \%)$ had active anal sex in the previous month. Ninety six $(27 \%)$ had active anal sex with a regular partner and 30 men $(8 \%)$ with a non-regular partner. Sixty three $(18 \%)$ had active anal sex without a condom. Unprotected active anal sex much more commonly happened with a regular partner ( 55 men, $15 \%)$ than with a non-regular partner (11 men, $3 \%$ ).

Men were also asked about sex in the previous year. Two hundred and thirteen men $(60 \%)$ had passive anal sex with men in the last year, more frequently occurring with regular partners (176 men, $49 \%$ ) than with non-regular partners (110 men, $31 \%)$. Similarly 224 men $(63 \%)$ reported active anal sex, more frequently occurring with regular partners $(183 \mathrm{men}$, $51 \%$ ) than with non-regular partners (106 men, 30\%).

Men were also asked how regularly they used condoms in anal sex in the previous year. Men were somewhat more likely to use condoms in anal sex when a non-regular rather than regular partner was involved (table 1).

\section{Heterosexual sex}

Fourteen men (4\%) had sex with a female partner in the previous month. Eleven of the sample $(3 \%)$ had penetrative vaginal sex, in all cases with a regular female partner. Seven $(64 \%)$ of the 11 men had vaginal sex without a condom. Nine (64\%) of the 14 men who had had sex with a woman and eight $(73 \%)$ of the 11 men who had vaginal sex described their sexual identity as bisexual. The remainder described themselves as gay. None of the men reported anal sex with a female partner in the previous month. Three men (1\%) who had sex with a female partner not involving vaginal sex reported masturbation as the primary sexual activity.

Thirty seven men $(10 \%)$ had sex with a female partner in the last year. In all but four cases, this had involved penetrative vaginal sex. Twenty seven men $(8 \%)$ had vaginal sex with a regular female partner and $11(3 \%)$ with a non-regular partner. Similar proportions of men said that they used condoms always, never or sometimes/often with regular female partners (table 1). However, half the men who had sex with a non regular female partner never used condoms. Six men $(2 \%)$ had anal sex with a female partner, five of them with a regular female partner. Three of the six men never used a condom in anal sex with a female partner. Three of the six men were gay and three bisexual.

Heterosexual sexual behaviour in the previous year was considered in relation to mens' preferred sexual identity. Twenty one $(57 \%)$ of the 37 men who had had sex with a woman identified themselves as bisexual. The other $16(43 \%)$ had described themselves as gay. Similarly $20(61 \%)$ of the 33 men who had vaginal sex identified themselves as bisexual.

In order to examine the diversity of sexual behaviour in the sample three groups were distinguished: (1)

Table 1 Use of condoms in last year

\begin{tabular}{|c|c|c|c|c|c|}
\hline & \multicolumn{5}{|c|}{ Regularity of use of condons $-N(\%)$} \\
\hline & Always & Often & Sometimes & Never & $\begin{array}{l}\text { Number of men having } \\
\text { this kind of sex }\end{array}$ \\
\hline \multicolumn{6}{|l|}{ Used in: } \\
\hline $\begin{array}{l}\text { Homosexual sex: } \\
\text { Passive anal sex-regular partners } \\
\text { Passive anal sex-non-regular partners } \\
\text { Active anal sex-regular partners } \\
\text { Active anal sex-non-regular partners }\end{array}$ & $\begin{array}{l}76(43) \\
63(57) \\
77(42) \\
68(64)\end{array}$ & $\begin{array}{l}18(10) \\
6(6) \\
10(6) \\
1(1)\end{array}$ & $\begin{array}{l}28(16) \\
23(21) \\
33(18) \\
20(19)\end{array}$ & $\begin{array}{l}54(31) \\
18(16) \\
63(34) \\
17(16)\end{array}$ & $\begin{array}{l}176 \\
110 \\
183 \\
106\end{array}$ \\
\hline $\begin{array}{l}\text { Heterosexual sex: } \\
\text { Vaginal sex-regular partner } \\
\text { Vaginal sex-non-regular partner }\end{array}$ & $\begin{array}{l}9(33) \\
2(18)\end{array}$ & $\begin{array}{l}6(22) \\
1(9)\end{array}$ & $\begin{array}{l}3(11) \\
2(18)\end{array}$ & $\begin{array}{l}9(33) \\
6(55)\end{array}$ & $\begin{array}{l}27 \\
11\end{array}$ \\
\hline
\end{tabular}


Table 2 Sexual orientation and aspects of recent and life time sexual history

\begin{tabular}{|c|c|c|c|}
\hline & \multicolumn{3}{|l|}{ Sexual orientation } \\
\hline & $\begin{array}{l}\text { Gay/homosexual } \\
(N=309)\end{array}$ & $\begin{array}{l}\text { Bisexual (self-ascribed) } \\
(N=31)\end{array}$ & $\begin{array}{l}\text { Bisexual (behaviour last year) } \\
(N=16)\end{array}$ \\
\hline $\begin{array}{l}\text { \% having homosexual passive anal sex in year } \\
\% \text { having homosexual active anal sex in year } \\
\text { Mean N (range) of male partners in year } \\
\text { Mean N (range) of female partners in year } \\
\% \text { having sex with female partner - life time }\end{array}$ & $\begin{array}{l}62 \%(192) \\
63 \%(196) \\
14 \cdot 8(0-248) \\
0.0(0) \\
52 \%(162)\end{array}$ & $\begin{array}{l}45 \%(14) \\
58 \%(18) \\
14 \cdot 8(0-98) \\
1.0(0-4) \\
100 \%(30)\end{array}$ & $\begin{array}{l}44 \%(7) \\
63 \%(10) \\
19 \cdot 4(0-82) \\
1 \cdot 8(1 \cdot 7) \\
100 \%(16)\end{array}$ \\
\hline
\end{tabular}

exclusively homosexual men $\mathrm{N}=309$ (2) men who described themselves as bisexual $(\mathrm{N}=31)$ and (3) men who in the last year were "behaviourally bisexual" that is, they had sex with both male and female partners, but did not view themselves as bisexual $(\mathbf{N}=16)$. Aspects of recent and life time sexual history were compared (table 2). Overall, whilst the frequency of homosexual passive anal sex are lower in the two bisexual groups, rates of active homosexual anal sex and numbers of male sexual partners in the last year are very similar. Similarly, patterns of life time history of STDs are similar between the three groups (table 3). One hundred and fifty eight men $(44 \%)$ had at least one HIV test and knew the result. Of those tested, 19 men $(12 \%)$ reported that they were HIV positive. It is difficult to attach significance to the high rate $(50 \%)$ of the "behaviourally bisexual" group who were HIV positive (table 2) because of the small numbers involved.

\section{Discussion}

These data provide further encouraging evidence of the changes in high risk homosexual anal sex that have occurred and which have recently been reflected in declining rates of STDs and stable or declining rates of HIV infection in this risk group. ${ }^{46}$ Thus much higher proportions of men report using condoms in anal sex in this sample compared with men attending a genitourinary medicine clinic surveyed in $1984 .^{6}$ High risk sex appears particularly to have been reduced with non-regular partners. Only $31 \%$ of this sample repor- ted passive anal sex with a non-regular partner compared with $70 \%$ of the gay men surveyed in a London genitourinary medicine clinic in $1987 .{ }^{4}$ On the other hand the overall frequency with which passive anal sex in the last year is reported $(60 \%)$ is not more favourable than that obtained $(41 \%)$ in a non-clinic survey of gay men conducted early in $1987 .{ }^{7}$

Sex with a female partner was reported by $4 \%$ of men for the previous month and $10 \%$ of men for the previous year. These figures are very similar to those obtained in a recent London clinic study of homosexual men of $5 \%$ and $10 \%$ respectively. ${ }^{4}$ Indeed the clinic study found that the rate of $10 \%$ of homosexual men reporting heterosexual activity in the previous year remained constant over the 3 years of the study. A much higher frequency of heterosexual activity was found in the DHSS non-clinic surveys of gay men in which $27-29 \%$ of men reported heterosexual sexual activity in the previous year. It is difficult to determine the extent to which these differences are due to variation in sampling between studies.

There is evidence that anal sexual intercourse may be an important risk factor in male to female transmission of HIV. ${ }^{89}$ Studies of HIV transmission in heterosexual couples have found rates of anal intercourse that vary from $4 \%{ }^{10}$ to $30 \% .^{8}$ A particularly high rate of heterosexual anal intercourse $(40 \%)$ was found amongst couples where the male partner was bisexual and it was suggested that bisexual men are more likely to engage in anal intercourse with their female partners than are men from other risk groups. ${ }^{8}$ In this study, although heterosexual anal intercourse

Table 3 Life time history of particular sexually transmitted diseases $-N$

\begin{tabular}{|c|c|c|c|}
\hline & $\begin{array}{l}\text { Gay/homosexual } \\
(N=309)\end{array}$ & $\begin{array}{l}\text { Bisexual (self-ascribed) } \\
(N=31)\end{array}$ & $\begin{array}{l}\text { Bisexual (behaviour last year) } \\
(N=16)\end{array}$ \\
\hline $\begin{array}{l}\text { Syphilis } \\
\text { Gonorrhoea } \\
\text { Hepatitis } \\
\text { Herpes } \\
\text { Genital warts } \\
\text { Non-specific urethritis } \\
\text { Non-specific proctitis } \\
\text { Thrush } \\
\text { HIV positive/N tested }\end{array}$ & $\begin{array}{l}12 \%(37) \\
28 \%(85) \\
13 \%(40) \\
7 \%(21) \\
19 \%(59) \\
36 \%(111) \\
4 \%(12) \\
11 \%(33) \\
10 \%(13 / 136)\end{array}$ & $\begin{array}{l}10 \%(3) \\
27 \%(8) \\
17 \%(5) \\
0 \%(0) \\
17 \%(5) \\
33 \%(10) \\
7 \%(2) \\
17 \%(5) \\
8 \%(1 / 12)\end{array}$ & $\begin{array}{l}19 \%(3) \\
25 \%(4) \\
6 \%(1) \\
13 \%(2) \\
19 \%(3) \\
50 \%(8) \\
13 \%(2) \\
19 \%(3) \\
50 \%(5 / 10)\end{array}$ \\
\hline
\end{tabular}


was infrequently reported for the previous year $(2 \%)$ and did not occur at all in a one month period prior to interview, nevertheless $6 / 37(16 \%)$ of men who had heterosexual sex in the previous year reported anal intercourse with a female partner. It was not associated with any particular sexual identity. More detailed studies of types of sexual behaviour are needed to clarify the precise mechanisms of male to female HIV transmission and the prevalence of these behaviours in populations. ${ }^{3}$

It is clear that there is no simple relationship between sexual identity and sexual behaviour. Thus one quarter of those who in the previous month had vaginal sex and one third of those who had vaginal sex in the previous year described their sexual identity as gay rather than bisexual. In the DHSS surveys also, fewer men classified themselves as bisexual than might be expected from their recent sexual behaviour. ${ }^{7}$ It is important for studies of sexual behaviour to be clear about which sense of this term is intended in describing sample characteristics.

There is evidence from a number of studies to suggest that amongst clinic attenders bisexual men have lower rates of antibodies to HIV. ${ }^{4112}$ This evidence has been interpreted firstly as suggesting that gay and bisexual men may be distinct populations ${ }^{4}$ and secondly that spread of HIV to heterosexuals may be limited. ${ }^{12}$ There are problems with both of these inferences. In many respects men who were behaviourally bisexual or who defined themselves as bisexual resembled the gay men in the sample. Most notably patterns of STDs in the three groups were similar. Also bisexual men were just as likely as gay men to have been the active partner in homosexual anal sex. Conversely many gay men had at some stage had sex with a female partner. It would require a longitudinal study to establish how stable are the sexual behaviour preferences of these men. In addition our data suggest that, whilst the most risky behaviour (homosexual passive anal sex) is somewhat less frequently reported by bisexual men, nevertheless, considerable numbers continue to put themselves at risk in this way. In this sense lower rates of HIV infection amongst men who are currently bisexual are not inevitable. Current and future behaviour patterns in response to public education will determine the extent to which differences in rates of HIV between groups continue.

The financial support of the MRC for the conduct of this survey is gratefully acknowledged.

\section{References}

1 Winkelstein W, Lyman D, Padian N, et al. Sexual practices and risk of infection by the human immunodeficiency virus. The San Francisco men's health study. JAMA 1987;257:321-5.

2 Moss A. AIDS and intravenous drug use: the real heterosexual epidemic. Br Med J 1987;294:389-90.

3 Johnson A. Heterosexual transmission of human immunodeficieny virus. Br Med J 1988;296:1017-9.

4 Evans B, McLean K, Dawson S, et al. Trends in sexual behaviour and risk factors for HIV infection among homosexual men, 1984-7. Br Med J 1989;298:215-8.

5 Blumstein P, Schwartz P. Bisexuality: some social psychological issues. J Soc Issues 1977;33:30-45.

6 Carne C, Weller I, Johnson A, et al. Prevalence of antibodies to human immunodeficiency virus, gonorrhoea rates, and changed sexual behaviour in homosexual men in London. Lancet 1987;i:656-8.

7 DHSS. AIDS: Monitoring response to the public education campaign, February 1986-February 1987. London: HMSO, 1987.

8 Padian N, Marquis L, Francis D, et al. Male to female transmission of human immunodeficiency syndrome. JAMA 1987;258:788-91.

9 European Study Group. Risk factors for male to female transmission of HIV. Br Med J 1989;298:411-5.

10 Peterman T, Stoneburner R, Allen J, et al. Risk of human immunodeficiency virus transmission from heterosexual adults with transfusion-associated infections. JAMA 1988;259:55-8.

11 Welch J, Palmer S, Banatvala J, et al. Willingness of homosexual and bisexual men in London to be screened for human immunodeficiency virus. Br Med J 1986;293:924.

12 Collaborative Study Group. HIV infection in patients attending clinics for sexually transmitted diseases in England and Wales. Br Med J 1989;298:415-8. 